\title{
Institutional Barriers Contribute to Low College Completion Rates
}

\author{
Lawrence Abele \\ Institute for Academic Leadership \\ Florida State University
}

\begin{abstract}
This essay identifies six common institutional barriers to student completion and offers recommendations to remove them. The barriers are: (a) confusing degree requirements, (b) courses not available when needed, (c) unnecessary registration holds, (d) course credits of transfer students not counted toward degree, (e) financial aid policies that disadvantage the neediest students, and (f) sample schedules that emphasize 12 rather than 15 credit hours per term, extending time and costs of the degree. Each of these barriers reduces student success, and while none is fatal, the cumulative effect can be substantial, especially on lower income students. Removing these and other potential barriers requires measuring every institutional action or decision against the question: Does this enhance student success? It includes reviewing every university process from course scheduling to financial services through the lens of a student. Is this business process transparent and accessible to students and is it even necessary? Does course scheduling meet the needs of every student to stay on track to graduate on time? Commitment involves challenging every statement that is used as an excuse or reason why something cannot be done that would enhance student success. Commitment means believing, and acting on the belief, that every student can be successful.
\end{abstract}

Keywords: graduation; college completion; institutional barriers

* Contact: labele@fsu.edu 
College completion rates are distressingly low in the United States despite efforts by institutions and foundations to improve graduation rates. On average, $40.4 \%$ of students who started at two-year schools and $69.6 \%$ of students who started at four-year schools earned a degree, not necessarily from the starting institution (Causey et al., 2020). Why is this? There is no single factor, but most discussions have focused on students and their academic preparation while devoting little consideration to institutional issues. Institutional policies can create barriers to completion and six are discussed here; none is intentional, and all can be relatively easily solved. There are also barriers to even entering college, though they are not discussed here (Schaffhauser, 2020; St. Amour, 2020).

Almost every campus discussion of low college graduation rates focuses on students, rather than on institutions, and generally concludes that poor academic preparation (Bromberg \& Theokas, 2016) is a major cause of the low rates. Any discussions on improving completion rates then invariably generate one of two responses: "get us better students" and/or "you just want us to lower standards." Both presidents and provosts have made similar comments along the lines of "What do you expect given the students we get?" These and similar responses do not contribute much to the solution as they imply that poor academic preparation is the driving cause of low graduation rates and thus absolves the institution of any responsibility.

In higher education we rarely test our ideas, and widespread comments about "poor academic preparation" are no exception. In fact, examination of a representative sample of 22,530 students across all types of institutions reveals that about $50 \%$ of students who leave college and never return are in good academic standing and $35 \%$ leave with A and B grades (Bryan et al., 2019). Clearly, at least half of the students who left had the academic preparation necessary for success. Keeping these academically talented students in college would benefit everyone. This is not to imply that other factors are not important, as considerations such as financial aid are clearly relevant.

If poor academic preparation is not the primary cause of low graduation rates, then what is? At my own institution, I worked for years with an incredible team on improving graduation rates with some success as the four-year rate improved from $42 \%$ to $62.1 \%$ (now $68 \%$ ) and the six-year rate improved from $63.8 \%$ to $79.4 \%$ (now $83 \%$; Hispanic rate $84 \%$, White rate $83 \%$, Black rate $80 \%$; College Navigator, 2020). I also spent time on more than two dozen other campuses studying graduation rates as well as discussing graduation rates with representatives of more than 50 institutions. Although many factors are involved, my conclusion is that institutions bear a significant portion of the responsibility for low graduation rates. Institutions, often unwittingly, create barriers that are largely invisible; none is fatal, but the cumulative effect can be devastating, especially to lower income students, and those barriers, described below, can be easily fixed.

The first barrier unintentionally created by institutions that students face is understanding degree requirements. Walk onto any campus and ask if the requirements to 
earn a degree are clear to students. The answer is, invariably, yes, and then you are directed to the requirements allegedly listed in the institution's catalog. Open that catalog yourself and try to determine the requirements to earn a degree in any field. They are pretty much incomprehensible: there are requirements set by the state, university, college, and department. Adding to the confusion, there are often hundreds of choices to fulfill the General Education requirements with little or no guidance to the student. Selecting the wrong courses can add a semester or more to the degree program. At best, degree requirements can only be navigated after considerable study.

There is a very low-cost solution to this barrier: degree maps. A degree map is a two- or four-year list of sequenced courses that are necessary to earn a degree, including "must take" courses enumerated by academic terms. Some schools are addressing the issues raised by this barrier and developing degree maps, but maps are not a cure-all. Institutional efforts and results can be uneven. Degree maps require a concentrated effort to develop and deploy. At times, maps can be incomplete and fail to highlight critical courses that must be taken in the academic term listed in order to graduate on time. Similarly, maps can overlook issues. There is also the problem of "hidden prerequisites," courses that are not listed as required in the catalog but are listed as required to take one of the required courses. Such difficulties are common but can be overcome with steady attention and leadership.

Once a student understands the requirements associated with degree completion, there is a second barrier. Students often find that a required course is not offered when needed or is offered without enough seats or is offered at a time that conflicts with other required courses. This is most common in the sciences where degree requirements overlap in several majors, but it occurs in all fields. Another common challenge is when a course is cancelled because of low enrollment, even when those few students enrolled need the course to graduate. Such difficulties must be addressed explicitly. Again, degree maps provide a useful tool. Academic maps not only offer a clear path to a degree, but they also can be used to track the number of students by major each term to determine the courses and number of seats needed. This allows the institution to meet the course needs of every student and help establish degree completion as an institutional priority.

There are further unintentional obstacles that an institution can tackle. One of the most frustrating is registration holds. Registration holds are institutional rules designed to stop students from registering until certain conditions (typically financial) have been met. These are widely abused and often unnecessary. Holds can be placed on registration for unpaid parking fines or other debt to the institution or for what seem to be trivial issues. It seems perverse that the student is prevented from paying the school tuition, usually $\$ 6,000$ or more, over a $\$ 25$ parking fine. Typically, the amounts owed are small, but the effect on students can be large. With registration holds in place, students often miss their assigned registration periods trying to sort this out, and, when they ultimately do register, many classes are full and unavailable. Nonetheless, students still need a fixed number of hours each term, often 12 to maintain full-time status. As 
a consequence, they complete their schedule with whatever courses they can enroll in and not ones necessary for graduation. This generates excess hours and prolongs their time in college, unnecessarily costing the student time and money. All this is done in the name of meeting certain, often minor conditions. This happens even though holds are not usually necessary because the institution controls the distribution of transcripts and degrees and can withhold both if needed.

Transfer students face additional barriers. Their treatment can fairly be called a national disgrace. In the process of transferring schools, students can lose a substantial number of the credits they have earned and for which they have already paid. According to the Government Accountability Office (2017), on average a student loses $43 \%$ of their credits when transferring and about $35 \%$ of all students transfer at least once. This is outrageous. It is even more outrageous when an upper division institution will not accept, what is, by most measures, the same course taken at the community college as that offered at the upper division school. At least half of the transfer students have had a Pell grant and two-thirds a Federal Direct Loan, thus a substantial proportion of lost credits have been paid for through federal financial aid. Ostensibly this issue has been addressed. Institutional articulation agreements and policies on transferring credits are required to be posted by the Higher Education Opportunity Act. Nonetheless, the reality is that its implementation is highly variable and often incomplete. Many schools state that they accept all transfer credits, but they place these credits in the "elective" category rather than counting them toward the degree. This adds to the problem of excess hours and prolongs the students' time in school.

Finances can be a significant barrier to attending college for many students and financial aid is critical if they are going to attend college. Experience shows, however, that institutional financial aid processes can work against those who need the assistance most. For example, many schools provide financial aid on a first come, first-served basis. This exacerbates the educational gap between high and low socioeconomic families because data show that the neediest students typically apply relatively late in the admissions cycle (Campus Logic, 2019) and therefore miss out on funds for which they otherwise would be eligible. This is the sort of unintentional obstacle that institutions can address. Holding some institutional or discretionary funds for need-based aid is a good, low-cost strategy to address the needs of students who apply late in the cycle for whatever reason. Other strategies are available as well. Remember that schools almost never consider all sources of aid when packaging financial aid. Such aid includes federal funds, state funds, institutional funds, and private funds held in the institution's foundation. Being purposeful in the coordinated use of these diverse sets of funds can help students stay on course and in school. Note, for example, the use of foundation resources. The foundations of larger institutions often have hundreds of thousands of dollars in unallocated aid since this source of funds often is not closely tracked or integrated into financial aid. Scholarships established years in the past are often neglected. Invariably some have criteria that are difficult to meet. Improving the use of such funds requires some administrative attention, but a relatively small investment in tracking all foundation funds can yield significant financial returns. These foundation funds 
can increase aid to students and may also be used for "graduation grants," usually a small amount of money that allows a student to complete college. In the same way, working out the relationships of federal, state, institutional, and private funds can pay real dividends to students struggling to stay in school.

The unintentional barriers to completion that students face are often embedded in institutional rules and culture. But they crop up elsewhere. For example, at many institutions the sample academic schedules for a term given to students consist of courses totaling 12 hours. This is not an unreasonable number on its face and is an approach adopted by many advisors and institutions. Depending on the institution it can fractionally lower tuition costs for a term, and it does reduce the academic demands on a student in the short term. Yet, it has unintended consequences. It ensures students will take longer to acquire all the hours necessary to graduate and increases the non-tuition costs associated with getting to completion which are considerable. These, in turn, help drive up the total costs of a degree and influence overall loan amounts. Remember that two-year degrees require a minimum of 60 hours and four-year degrees a minimum of 120 hours. These effects can be addressed. The most effective way to reduce the overall cost of college, minimize student debt, and make the best use of scholarship monies is for undergraduate students to graduate on time. For most disciplines, that means earning 30 credits a year, preferably by earning 15 credits a term. Institutions though can be reluctant to encourage this path.

There are two observations commonly made on campus as to why the norm of 15 hours per term should not be recommended, and both involve testable hypotheses. The first is: "All of our students work and therefore cannot take 15 hours." Perhaps, but it is important to verify this with independent verifiable data rather than merely surveying students. This can be done by having student data checked by the state labor department. It is highly likely that many fewer students are employed than was anticipated; only 43\% of full-time students were employed in 2018 while $81 \%$ of part-time students were employed (National Center for Education Statistics, 2020). Regardless of the results, your inquiry can inform your academic scheduling and influence the institution's approach to other activities. The second is: "Our students are not strong enough to handle 15 hours." Again, check. Test this by comparing academically matched students who took 15 or more hours with those who took less than 15 hours. In my experience, every time this has been done, students taking 15 or more hours earn more credits, have higher grades, and have higher retention rates than similarly matched students who take fewer hours (Bousquet et al., 2014; University of Hawaii System, 2012a, $2012 \mathrm{~b})$. Students at schools promoting 15 hours generally find the same positive results.

Most of these barriers (and others) to completion can be fixed at little or no cost. The key: the leadership of the institution must have an unwavering commitment to student success. Commitment means measuring every action or decision against the question: Does this enhance student success? The answer to this question depends on collecting 
and analyzing detailed data on all aspects of students as they move toward graduation. It includes reviewing every university process from course scheduling to financial services through the lens of a student. Is this business process transparent and accessible to students and is it even necessary? Does course scheduling meet the needs of every student to stay on track to graduate on time? Commitment involves challenging every statement that is used as an excuse or reason why something cannot be done that would enhance student success. Commitment means believing, and acting on the belief, that every student can be successful.

\section{Acknowledgements}

I thank Ellyn Artis, Robert Bradley, Timothy Renick, and anonymous reviewers for valuable comments and especially the staff of the National Center for Educational Statistics for analyzing grades from the Beginning Postsecondary Students Longitudinal Study.

\section{References}

Bousquet, D., Harris, L., \& Saltonstall, M. (2014). 15 credits per semester, the key to student Progress. NASPA Leadership Exchange, Winter. https://conference2018. naspa.org/publications/leadership-exchange

Bromberg, M., \& Theokas, C. (2016). Meandering toward graduation: transcript outcomes for high school graduates. The Education Trust. https://edtrust.org/wp-content/uploads/2014/09/MeanderingTowardGraduation_EdTrust_April2016.pdf.

Bryan, M., Cooney, D., \& Elliott, B. (2019). Beginning postsecondary students longitudinal study. National Center for Education Statistics. https://nces.ed.gov/ pubs2020/2020522.pdf

Campus Logic. (2019). Timing is everything: FAFSA filing trends: Patterns in the filing of the FAFSA during the 2018-19 aid year. https:/campuslogic.com/resources/ data-snapshot-download

Causey, J., Huie, F., Lang, R., Ryu, M., \& Shapiro, D. (2020). Completing college 2020: A national view of student completion rates for 2014 entering cohort (Signature report 19). National Student Clearinghouse Research Center. https:/ nscresearchcenter.org/wp-content/uploads/Completions_Report_2020.pdf.

College Navigator. (2020). https://nces.ed.gov/ collegenavigator/?q=Florida+state+university\&s=all\&id=134097

Government Accountability Office. (2017). Students need more information to help reduce challenges in transferring college credits. https://www.gao.gov/products/ GAO-17-574

National Center for Educational Statistics. College Student Employment. (2020). https://nces.ed.gov/programs/coe/indicator_ssa.asp 
Schaffhauser, D. (2020). Report: Top 4 barriers to college completion. https://campustechnology.com/articles/2020/11/20/report-top-4-barriers-to-college-completion.aspx

St. Amour, M. (2020). Survey: Self-doubt is a barrier to college. https://www.insidehighered.com/news/2020/07/15/barriers-higher-education-not-just-financial-also-emotional

University of Hawaii System. (2012a). An examination of academic performance by the 15-credit hour breakpoint for first-time freshmen at the UH community colleges, fall 2009 to fall 2011. Institutional Research and Analysis Office, University of Hawaii System.

University of Hawaii System. (2012b). An examination of academic performance by the 15-credit hour breakpoint for first-time freshmen at the UH four-year campuses, fall 2009-fall 2011. Institutional Research and Analysis Office, University of Hawaii System. 